\title{
A Combined Raman Spectroscopic and Thermogravimetric Analysis Study on Oxidation of Coal with Different Ranks
}

\author{
Weiqing Zhang, ${ }^{1}$ Shuguang Jiang, ${ }^{1,2}$ Christopher Hardacre, ${ }^{3}$ Peter Goodrich, ${ }^{3}$ \\ Kai Wang, ${ }^{2}$ Hao Shao, ${ }^{2}$ and Zhengyan $\mathrm{Wu}^{2}$ \\ ${ }^{1}$ State Key Laboratory of Coal Resources and Safe Mining, China University of Mining and Technology, Xuzhou 221116, China \\ ${ }^{2}$ School of Safety Engineering, China University of Mining and Technology, Xuzhou 221116, China \\ ${ }^{3}$ School of Chemistry and Chemical Engineering/QUILL, Queen's University Belfast, Belfast BT9 5AG, UK \\ Correspondence should be addressed to Shuguang Jiang; jsguang@cumt.edu.cn and Christopher Hardacre; c.hardacre@qub.ac.uk
}

Received 12 September 2015; Accepted 4 November 2015

Academic Editor: Christos Kontoyannis

Copyright (C) 2015 Weiqing Zhang et al. This is an open access article distributed under the Creative Commons Attribution License, which permits unrestricted use, distribution, and reproduction in any medium, provided the original work is properly cited.

\begin{abstract}
Raman spectroscopy and nonisothermal thermogravimetric analysis (TGA) measurements have been reported for different rank coals (lignite, bituminous coal, and anthracite) and the relationship between the measurements was examined. It was found that the Raman spectra parameters can be used to characterize structure changes in the different rank coals, such as the band area ratios based on the curve-fitted results. Higher ranked coal was found to have higher values of $I_{\mathrm{GR}} / I_{\mathrm{All}}$ and $I_{(\mathrm{G}+\mathrm{GR})} / I_{\mathrm{All}}$ but lower values of $I_{\mathrm{D}} / I_{(\mathrm{G}+\mathrm{GR})}, I_{\mathrm{DL}} / I_{(\mathrm{G}+\mathrm{GR})}, I_{(\mathrm{S}+\mathrm{SL})} / I_{(\mathrm{G}+\mathrm{GR})}$, and $I_{\left(\mathrm{GL}+\mathrm{GL}^{\prime}\right)} / I_{(\mathrm{G}+\mathrm{GR})}$. The oxidation properties of the coal samples were characterized by the reactivity indexes $T_{\mathrm{ig}}, T_{20 \%}$, and $T_{\max }$ from TGA data which were found to correlate well with the band area ratios of $I_{\mathrm{GR}} / I_{\mathrm{All}}$, $I_{(\mathrm{G}+\mathrm{GR})} / I_{\mathrm{All}}$, and $I_{(\mathrm{S}+\mathrm{SL})} / I_{(\mathrm{G}+\mathrm{GR})}$. Based on these correlations, the Raman band area ratios were found to correlate with the oxidation activity of coal providing additional structural information which can be used to understand the changes in the TGA measurements.
\end{abstract}

\section{Introduction}

Coal can, and often does, undergo substantial oxidation after exposure to air under ambient conditions. This has been recognized as one of the primary reasons responsible for the self-heating of coal and, in extreme cases, the spontaneous combustion of coal in mines and stock piles $[1,2]$. In general, the rate of oxygen consumption by coal decreases with an increase in the carbon content (coal rank) of the sample [3-5]. Therefore, an understanding of the relationship between the oxidation properties of coal and differences in the coal structure is important in order to determine which features are most relevant to the spontaneous combustion of coal.

Commonly, Fourier transform infrared (FTIR) spectroscopy, X-ray diffraction (XRD), and Raman spectroscopy are used in the study of the coal structure [6-13]. Raman spectroscopy provides information about both the crystalline structure and the molecular structure and thus is used most extensively [14-17]. For example, coals show a band at about $1580 \mathrm{~cm}^{-1}$ assigned to the stretching vibration mode with $E_{2 \mathrm{~g}}$ symmetry in the aromatic layers of the graphite crystallites $[14,15]$. This feature, denoted by $G$ band $[6,8]$, is attributed to the graphite found in higher rank anthracite type coals. For lower rank coals or disordered carbonaceous materials, an additional band appears at about $1350 \mathrm{~cm}^{-1}$, denoting the disordered or defect band (D band) $[6,8]$. This is related to the disordered graphitic lattice vibration mode with $A_{1 \mathrm{~g}}$ symmetry $[10,14,15]$ and represents the in-plane imperfections such as substitutional heteroatoms, grain boundaries, vacancies, or other defects in microcrystalline lattices $[18,19]$. Normally, G and $\mathrm{D}$ bands of the highly disordered carbon materials are broad and "overlap" with each other. Thus, deconvolution of the Raman spectra is essential.

A number of detailed studies have been undertaken to assign the features observed in the Raman spectra. For example, Beyssac et al. [20] used Raman microspectroscopy with an excitation wavelength of $514.5 \mathrm{~nm}$ to characterize disordered and heterogeneous carbonaceous materials and assigned four bands at around 1150,1350,1500, and $1620 \mathrm{~cm}^{-1}$ to defects in poorly organized carbonaceous materials or 
microcrystalline graphite as well as the commonly observed $\mathrm{G}$ band at $1580 \mathrm{~cm}^{-1}$ band. Sadezky et al. [18] investigated the Raman spectra of soot and related carbonaceous materials with a Raman microscope operated at 514, 633, and $780 \mathrm{~nm}$ and fitted the spectra by five bands at about 1200, 1350, 1500, 1580 , and $1620 \mathrm{~cm}^{-1}$. Sheng [16] fitted the Raman spectra of coal char, measured by a Raman microscope with an excitation wavelength of $514.5 \mathrm{~nm}$, and obtained five bands around 1150,1350,1530,1580, and $1620 \mathrm{~cm}^{-1}$ based on the results of references $[18,20]$. In these reports, the bands at $1150-1200 \mathrm{~cm}^{-1}$ were observed in poorly crystalline carbonaceous materials and have been generally attributed to $\mathrm{sp}^{2}$ $\mathrm{sp}^{3}$ mixed sites at the periphery of crystallites or to $\mathrm{C}-\mathrm{C}$ and $\mathrm{C}=\mathrm{C}$ stretching vibrations of polyene-like structures [18-22]. The bands between 1500 and $1550 \mathrm{~cm}^{-1}$ have been assigned to amorphous $\mathrm{sp}^{2}$-bonded forms of carbon, such as organic molecules, fragments, or functional groups $[16,18,20]$. The $1620 \mathrm{~cm}^{-1}$ band was present as a shoulder on $G$ band and is not well understood currently. However, this band was always found to be present when D band is observed and its intensity decreased with increasing degrees of order $[15,18$, 20]. Sonibare et al. [23] recorded the Raman spectra of six Nigerian coals ranging from subbituminous to bituminous by a Raman microscope with an excitation wavelength of $532.21 \mathrm{~nm}$ and fitted the high signal intensity between $\mathrm{G}$ and $\mathrm{D}$ bands maxima with one band between 1500 and $1550 \mathrm{~cm}^{-1}$ and assigned this feature to amorphous $\mathrm{sp}^{2}$-bonded forms of carbon. Li et al. [17] measured the coal char using a Fourier transform Raman spectrometer with an excitation wavelength of $1064 \mathrm{~nm}$ and deconvoluted the spectra with a total of 10 bands. The 10 bands were associated with 4 main assignments, namely, $\mathrm{G}$ band, $\mathrm{D}$ band, three peaks at 1540,1465 , and $1380 \mathrm{~cm}^{-1}$ in the overlapping $G$ and $D$ bands region together assigned to 3-5 membered aromatic rings and methylene or methyl aromatic rings with mixed $\mathrm{sp}^{2}-\mathrm{sp}^{3}$ structures, and $\mathrm{S}$ band at $1185 \mathrm{~cm}^{-1}$ representing $\mathrm{sp}^{2}-\mathrm{sp}^{3}$ carbonaceous structures, which is the same as the references of $[18,20]$. Whilst there is some variation in the assignments and deconvolution of the Raman features, it is clear that these measurements may be employed to determine the degree of order within the carbon structure of coal [11]. Herein, three different coal samples were examined using Raman spectroscopy to characterize the differences in the coal microstructure as a function of the coal rank. From this information, a correlation between the structural characteristics and the oxidation properties of coal was obtained.

\section{Experimental}

Three samples of coal with different rank, lignite, bituminous coal, and anthracite from China, were used as received in this study. The main coal quality parameters for each sample are summarized in Table 1. Prior to measurement, each sample was milled and sieved to a particle size of $150-$ $250 \mu \mathrm{m}$ and then analyzed using Raman spectroscopy and thermogravimetric analysis (TGA).

The Raman spectra were measured in the range of 1000$2000 \mathrm{~cm}^{-1}$ using PerkinElmer RamanStation $400 \mathrm{~F}$ dispersive
TABLE 1: Main coal quality indexes of coal samples.

\begin{tabular}{lccc}
\hline Coal quality parameters & \multicolumn{3}{c}{$\begin{array}{c}\text { Samples } \\
\text { Lignite }\end{array}$} \\
& Bituminous coal & Anthracite \\
\hline Analysis (\%) & 17.75 & 4.44 & 5.06 \\
$\quad$ Moisture & 20.86 & 21.59 & 16.55 \\
Ash & 36.22 & 30.74 & 5.20 \\
Volatile matter & 25.16 & 43.23 & 73.18 \\
Fixed carbon & 3.85 & 4.37 & 2.29 \\
Hydrogen (\%) & 21.18 & 25.47 & 27.36 \\
Heat of combustion $\left(\mathrm{MJ} \mathrm{kg}^{-1}\right)$ &
\end{tabular}

spectrometer (PerkinElmer, UK) operating at $100 \mathrm{~mW}$ with an excitation wavelength of $785 \mathrm{~nm}$. The exposure time and number of exposures were set to $5 \mathrm{~s}$ and 5 , respectively, operating with a sampling spot size of $100 \mu \mathrm{m}$. To ensure that the spectra were representative of the whole of the sample, spectra from seven different samples from each rank coal were taken, and each spectrum was deconvoluted using the Omnic 8.0 package using eight Gaussian bands according to the method reported by Li et al. [17]. In the coal samples analyzed herein, a new band $\left(\sim 1800 \mathrm{~cm}^{-1}\right)$ located on the left of GL band $\left(\sim 1710 \mathrm{~cm}^{-1}\right)$ is more obvious compared with the spectra of coal char characterized by Li et al. [17]. Another difference is the number of curve-fitted bands between $\mathrm{D}$ and G bands. Typically three bands were curve-fitted in [17], while only two bands were used in this study. Curve fitting with three bands was initially examined; however, statistically nonsignificant improvement was obtained with three bands and, therefore, the minimum number of bands, that is, two, was used in the deconvolution between D and G features in the present study. For each coal, the mean value and the standard deviation of each of the band area ratios were calculated over the 7 samples of each coal measured.

TGA is one of the most commonly used methods to study the oxidation properties of coal $[24,25]$. Nonisothermal TGA measurements were carried out using a thermogravimetric analyzer (TGA/DSC 1 Star System, Mettler Toledo, Switzerland) in flowing dry air at $50 \mathrm{~cm}^{3} \mathrm{~min}^{-1}$ at heating rates of 1 and $10^{\circ} \mathrm{C} \mathrm{min}^{-1}$ over the temperature range of $25-850^{\circ} \mathrm{C}$.

\section{Results and Discussion}

3.1. Raman Spectra. Figure 1 shows average of the Raman spectra from the seven samples examined of each rank coal and the corresponding deconvolution of the features. It is shown that the Raman spectra could be successfully curvefitted with eight Gaussian bands.

$\mathrm{GL}^{\prime}$ and GL bands shown in Figure 1 at 1810 and $1710 \mathrm{~cm}^{-1}$, respectively, represent oxygen-containing species within the structure [17]. $G$ band at $1600 \mathrm{~cm}^{-1}$ has been unambiguously assigned to the crystalline graphite $E_{2 \mathrm{~g} 2}$ vibration $[13,16-22]$. GR band at $1560 \mathrm{~cm}^{-1}$ denotes the presence of aromatic ring systems with more than two fused benzene rings typically found in amorphous carbon structures according to $[16-18,20,23]$. It is believed that the combined intensity of $\mathrm{G}$ and GR bands indicates the total 


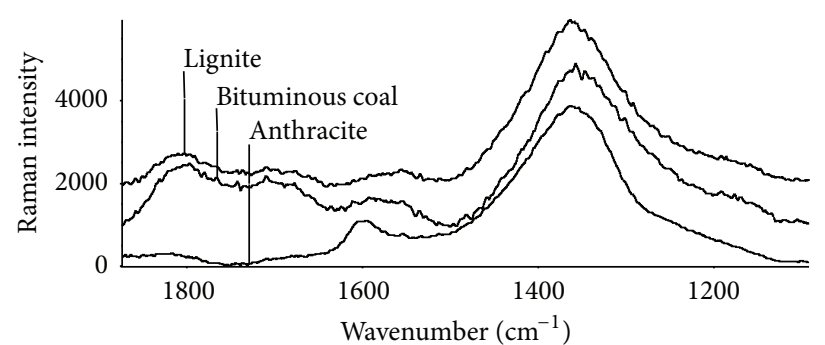

(a)

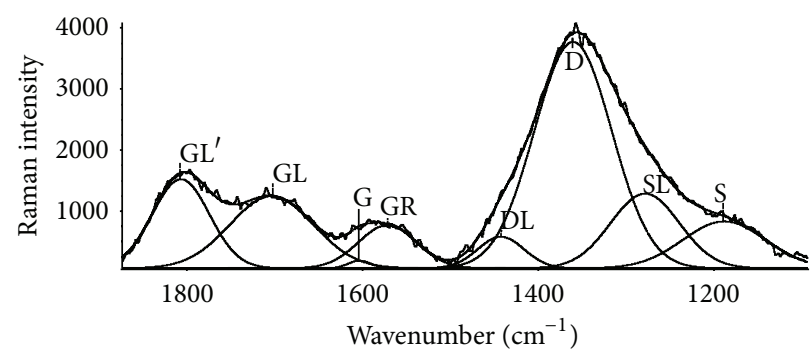

(c)

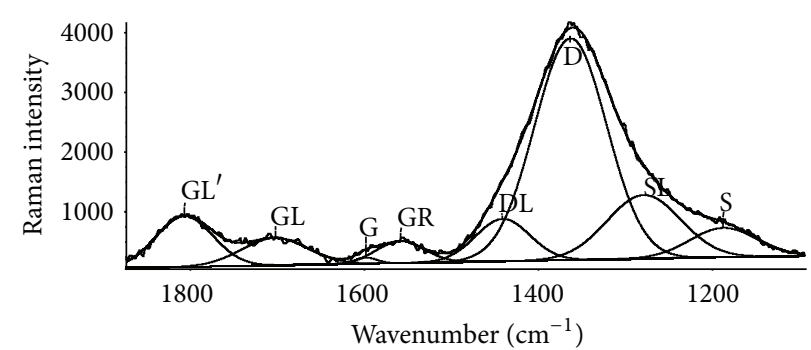

(b)

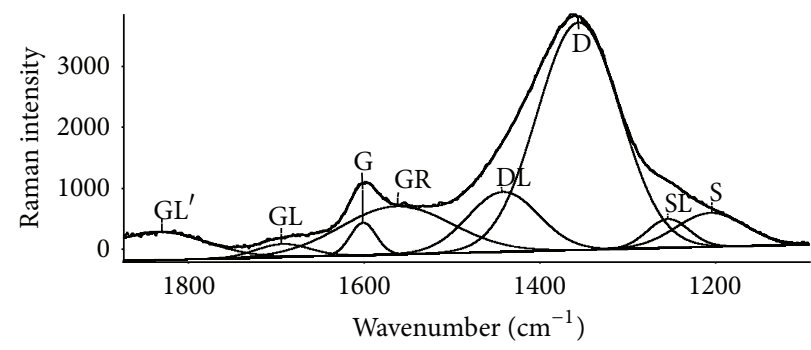

(d)

FIGURE 1: (a) Average Raman spectra of the three coals and deconvolution of the features associated with (b) lignite, (c) bituminous coal, and (d) anthracite.

amount aromatic ring systems in the coal. DL band centered at $1440 \mathrm{~cm}^{-1}$ represents amorphous structures, such as $\mathrm{sp}^{2}$-bonded forms of carbon originated from organic molecules, fragments, or functional groups $[16,23]$. D band at $1360 \mathrm{~cm}^{-1}$ shows defect structures in the graphite structure and the presence of medium-to-large sized $(\geq 6)$ aromatic ring systems [13-23]. The shoulder, $\mathrm{S}$, at $1190 \mathrm{~cm}^{-1}$ has been commonly attributed to $\mathrm{sp}^{2}-\mathrm{sp}^{3}$ carbonaceous structures, such as $\mathrm{C}_{\text {aromatic }}-\mathrm{C}_{\text {alkyl }}$, aromatic/aliphatic ethers, C-C on hydroaromatic rings, and $\mathrm{C}-\mathrm{H}$ on aromatic rings [17]. SL band at $1280 \mathrm{~cm}^{-1}$ represents ether related structures $[16-18,20]$.

From Figures 1(b)-1(d), it is clear that $\mathrm{G}$ band is much weaker compared with $\mathrm{D}$ band in lignite and bituminous coal, implying poor crystallinity in these latter two coal samples. In anthracite, $\mathrm{G}$ band is more pronounced, showing the presence of high crystallinity. Since GR band is more intense than G band in each of the samples measured, this indicates that the fused benzene rings are the main aromatic structures within the coal. The intensities of GL' and GL bands are more pronounced in lignite and bituminous coal than that found in anthracite, showing more oxygen-containing structures in the lower rank coals. Furthermore, S and SL bands in lignite and bituminous coals are also higher in intensity compared with anthracite indicating higher amounts of amorphous forms of carbon in the lower rank coal samples.

Further information can be obtained by analyzing the band area ratio, which is a combined parameter of the band intensity and FWHM and thus is more sensitive to the carbon structures present [16]. Therefore, the band areas associated with G and GR features were summed to provide an indication of the aromatic ring systems in the coal. Similarly, the combined band area of S and SL was obtained as this has been reported to give an indication of the defects responsible for the oxidation of the coal [16]. The combination of GL' and
GL bands represents the oxygen-containing structure in coal. The area ratios for these combinations are shown in Figure 2.

It can be seen that the higher ranked coals have higher values of $I_{\mathrm{GR}} / I_{\mathrm{All}}$ and $I_{(\mathrm{G}+\mathrm{GR})} / I_{\mathrm{All}}$ but lower values of $I_{\mathrm{D}} / I_{(\mathrm{G}+\mathrm{GR})}, I_{\mathrm{DL}} / I_{(\mathrm{G}+\mathrm{GR})}, I_{(\mathrm{S}+\mathrm{SL})} / I_{(\mathrm{G}+\mathrm{GR})}$, and $I_{\left(\mathrm{GL}+\mathrm{GL}^{\prime}\right)} / I_{(\mathrm{G}+\mathrm{GR})}$. These changes in the ratios indicate that more ordered carbon structures and structural defects/imperfections in the carbon crystallites occur as coal rank increases during coalification. This is consistent with the results reported by Nestler et al. for the structural evolution for a range of ranked coals [23, $26]$. The ratio of $I_{\mathrm{D}} / I_{(\mathrm{G}+\mathrm{GR})}$, in general, shows an inverse relationship with the crystallite size of the carbon in the coal $[16,23]$. The decrease in $I_{\mathrm{D}} / I_{(\mathrm{G}+\mathrm{GR})}$ with increasing coal rank indicates an increase in the average crystalline size of the coal. In addition, the decrease of $I_{(\mathrm{S}+\mathrm{SL})} / I_{(\mathrm{G}+\mathrm{GR})}$ with increasing coal rank demonstrates that amorphous phase of carbon transforms into a crystalline form under the coalification process. $I_{\mathrm{DL}} / I_{(\mathrm{G}+\mathrm{GR})}$ reduces significantly in both bituminous coal and anthracite compared with that found in lignite sample, showing a significant decrease in $\mathrm{sp}^{2}$ carbon sites of the two higher rank coals. Furthermore, the oxygen-containing structures are found to be significantly reduced in anthracite compared with lignite and bituminous coals as shown by $I_{\left(\mathrm{GL}+\mathrm{GL}^{\prime}\right)} / I_{(\mathrm{G}+\mathrm{GR})}$ value. These results also indicate a more ordered coal structure is present as the coal rank increases which leads to the increase in $I_{(\mathrm{G}+\mathrm{GR})} / I_{\mathrm{All}}$ ratio observed. These results are consistent with previously reported XRD results obtained from a range of semianthracite and bituminous coals showing the evolution of coal structure as a function of fraction of amorphous carbon, aromaticity, and crystallite size [27]. Accordingly, the band area ratios may be used for evaluating the reactivity of coals as some ratios, such as $I_{\mathrm{GR}} / I_{\mathrm{All}}, I_{(\mathrm{G}+\mathrm{GR})} / I_{\mathrm{All}}$, and $I_{(\mathrm{S}+\mathrm{SL})} / I_{(\mathrm{G}+\mathrm{GR})}$, change regularly with increasing coal rank. 


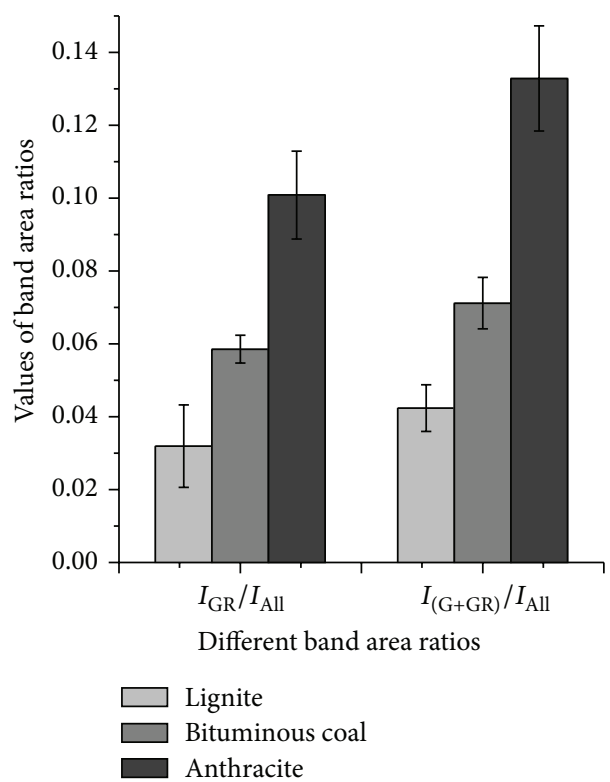

(a)

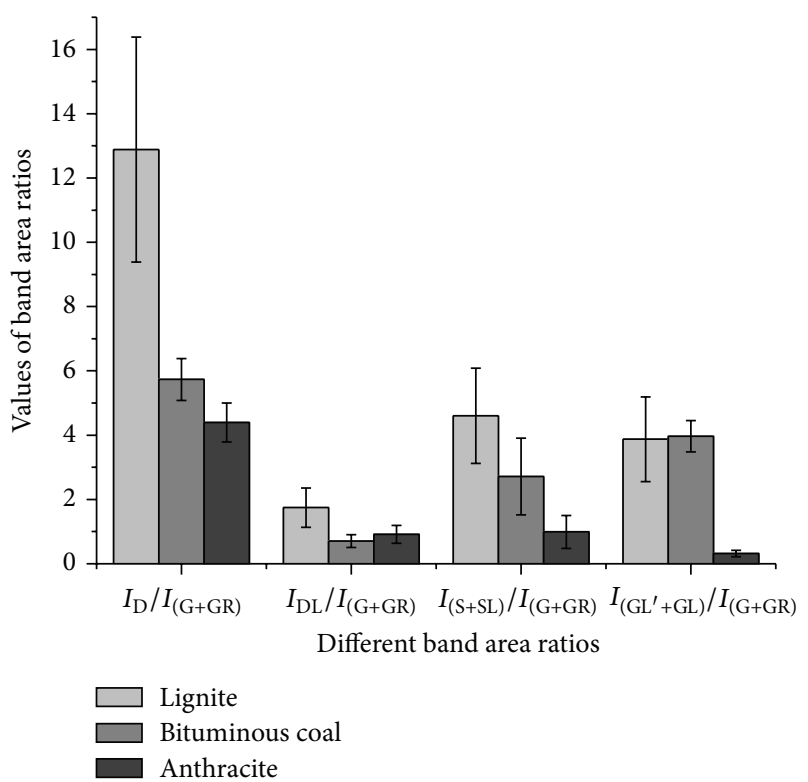

(b)

FIGURE 2: Band area ratios of (a) $I_{\mathrm{GR}} / I_{\mathrm{All}}$ and $I_{(\mathrm{G}+\mathrm{GR})} / I_{\mathrm{All}}$ and (b) $I_{\mathrm{D}} / I_{(\mathrm{G}+\mathrm{GR})}, I_{\mathrm{DL}} / I_{(\mathrm{G}+\mathrm{GR})}, I_{(\mathrm{S}+\mathrm{SL})} / I_{(\mathrm{G}+\mathrm{GR})}$, and $\left.I_{(\mathrm{GL}+\mathrm{GL}}\right) / I_{(\mathrm{G}+\mathrm{GR})}$ for different rank coals. The error bars show the standard deviations of the parameters for each coal sample.

3.2. TGA Results. Figure 3 shows the TGA results of the coal samples at $1^{\circ} \mathrm{C} \mathrm{min}{ }^{-1}$ and $10^{\circ} \mathrm{Cmin}^{-1}$. As shown in Figures $3(\mathrm{a})$ and $3(\mathrm{~b})$, the TGA profiles of each of the different rank coal samples are significantly different. At heating rate of $1^{\circ} \mathrm{C} \mathrm{min}^{-1}$, all the coals undergo an increase in mass before a sharp mass loss which appears at elevated temperatures. This change has been reported previously and is thought to be caused by the chemisorption of oxygen on the coal surface and, thereafter, the formation of solid oxygenated surface complexes $[1,28]$. From Figure 3(c), the amount of mass gained increases with increasing coal rank, which is consistent with previously reported results. Although the extent of the mass increase does give some information regarding the oxidative stability of the coal, such techniques give us limited information about the chemical nature of the coal, because the chemisorption ability of coal is closely related with the coal physical structure, which can be characterized by the porosity and internal surface area $[29,30]$. In addition, these results may be complicated by volatilization of molecules from the coal which will lead to a decrease in the mass and therefore reducing the overall effect of the chemisorption of oxygen. For example, the largest mass increases anthracite which also contains the lowest amounts of volatile material (Table 1) and, therefore, it may be that the increase is more visible in this case.

For all the coal samples examined, with increasing temperature, the decomposition of the solid oxygenated complexes and direct interaction of the coal with oxygen dominates, leading to a sharp mass loss. Unsurprisingly, with increasing coal rank, the sharp mass loss shifts to higher temperatures, which shows that the oxidation stability of coal is higher as coal rank increases. Figure 3(d) shows that, at a higher heating rate $\left(10^{\circ} \mathrm{C} \mathrm{min}^{-1}\right)$, the mass gain was not present in lignite sample and significantly reduced in the other two coal samples compared with the profiles observed at $1^{\circ} \mathrm{C} \mathrm{min}{ }^{-1}$. This indicates that the experimental conditions, such as heating rate, can dramatically influence the TGA profiles. For example, as the heating rate increases, the corresponding coal stability moves significantly towards higher temperature and the mass gain decreases for the same rank coal (Figure 3(a)). This phenomenon is caused by the increase in thermal hysteresis in coal sample and the shorter chemical absorption time allowed at higher heating rate. However, it must be stressed that the oxidation properties of different coals must be compared under the same experimental conditions, that is, heating rate.

From the TGA and differential TGA curves, reactivity indexes which are related to the oxidation properties of coal can be calculated [31-34]. These provide a measure of the spontaneous ignition temperature of maximum coal mass $\left(T_{\mathrm{ig}}\right)$, the temperature at which $20 \%$ conversion $\left(T_{20 \%}\right)$ occurs, and the peak temperature of maximum mass loss rate $\left(T_{\max }\right)$. These results are summarized in Table 2 for each coal sample. As expected, as the rank of the coal samples increases, the reactivity index value is higher, and accordingly the coal oxidation reactivity is lower.

3.3. Correlation between Reactivity Indexes of Coal and Raman Band Area Ratios. In order to examine whether the Raman spectra measured and the reactivity indexes could be related, the five reactivity indexes $\left(T_{\mathrm{ig}}\left(1^{\circ} \mathrm{C} \mathrm{min}^{-1}\right), T_{20 \%}\left(1^{\circ} \mathrm{C} \mathrm{min}{ }^{-1}\right)\right.$, $T_{20 \%}\left(10^{\circ} \mathrm{C} \mathrm{min}^{-1}\right), T_{\max }\left(1^{\circ} \mathrm{C} \mathrm{min}^{-1}\right)$, and $\left.T_{\max }\left(10^{\circ} \mathrm{C} \min ^{-1}\right)\right)$ were plotted against the Raman band area ratios $\left(I_{\mathrm{GR}} / I_{\mathrm{All}}\right.$, $I_{(\mathrm{G}+\mathrm{GR})} / I_{\mathrm{All}}$, and $\left.I_{(\mathrm{S}+\mathrm{SL})} / I_{(\mathrm{G}+\mathrm{GR})}\right)$. Figure 4 shows that, in general, the reactivity indexes were found to increase with increases in $I_{\mathrm{GR}} / I_{\mathrm{All}}$ and $I_{(\mathrm{G}+\mathrm{GR})} / I_{\mathrm{All}}$ and decrease with 


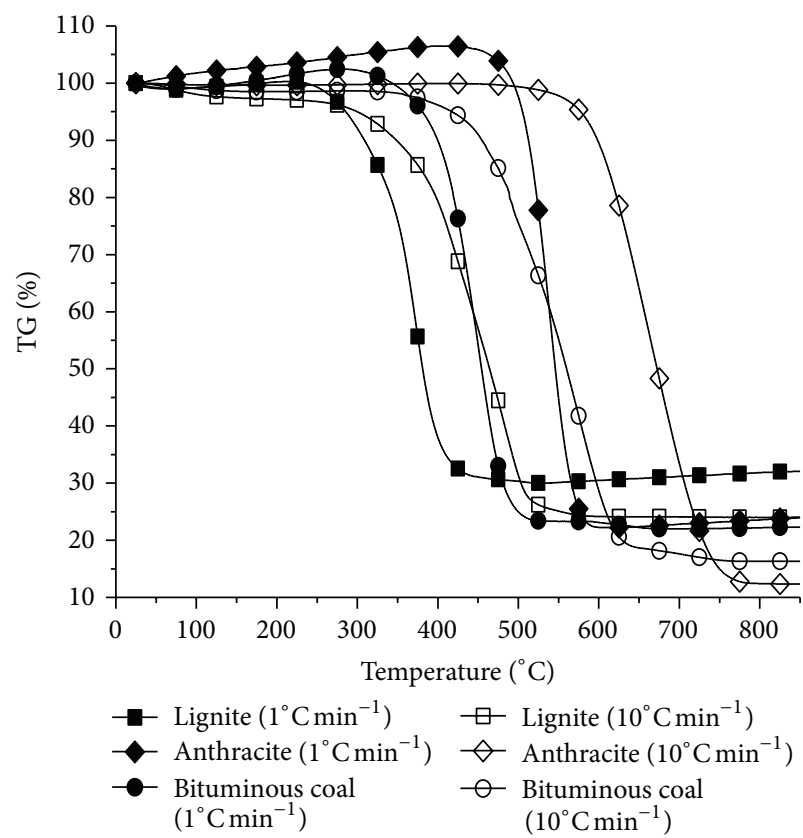

(a)

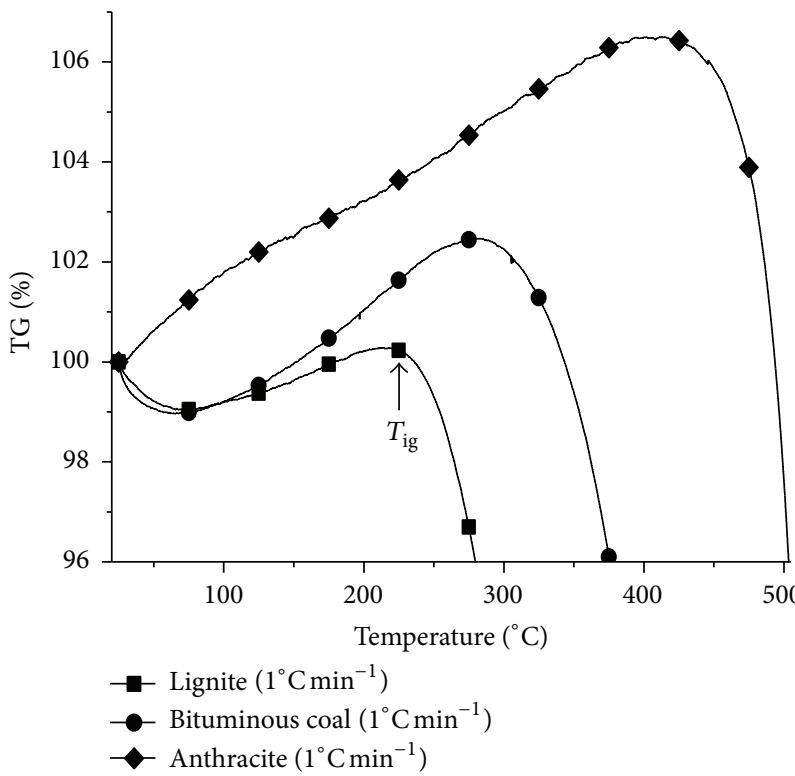

(c)

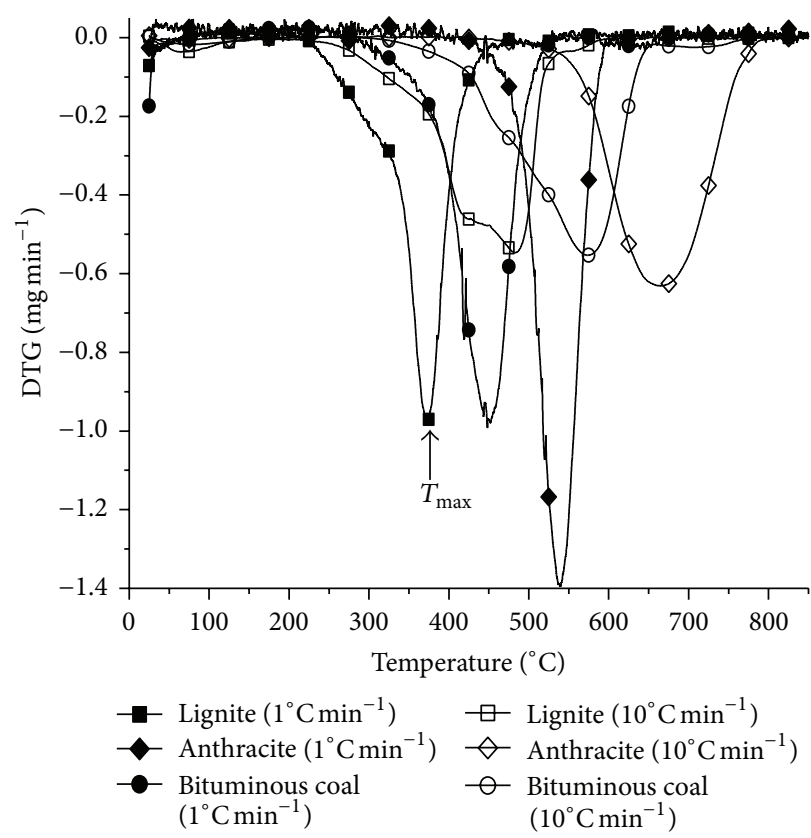

(b)

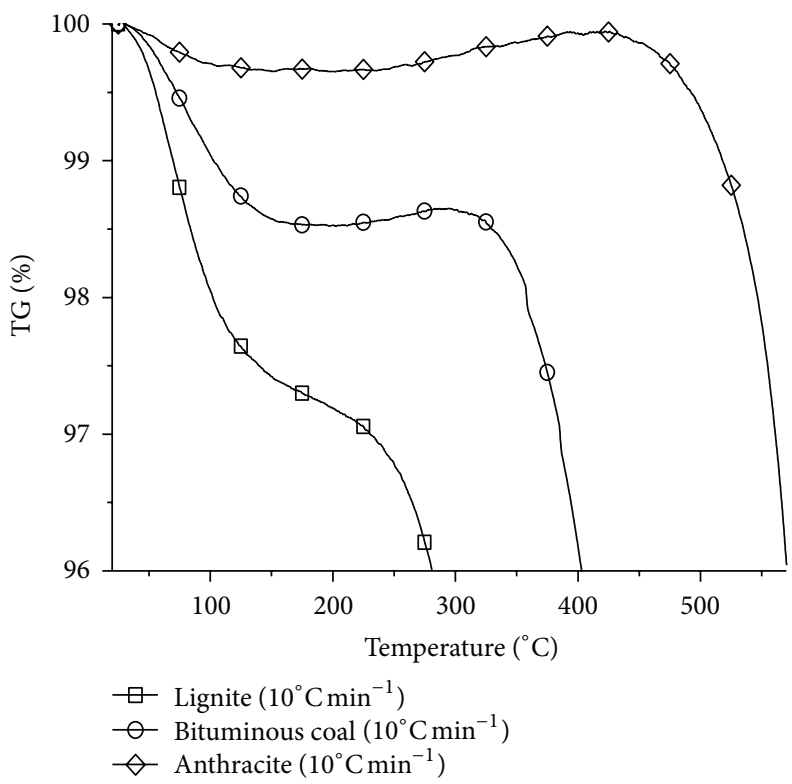

(d)

FIGURE 3: (a) TGA results of the coal samples. (b) Differential TGA (DTG) of the coal samples. (c) TGA over the range of 96-107\% mass change at $1^{\circ} \mathrm{C} \mathrm{min}^{-1}$. (d) TGA over the range of $96-100 \%$ mass change at $10^{\circ} \mathrm{C} \mathrm{min}^{-1}$.

increase in $I_{(\mathrm{S}+\mathrm{SL})} / I_{(\mathrm{G}+\mathrm{GR})}$. The higher integrated intensity of the defect and amorphous bands and the lower integrated intensity of G and GR bands indicate less ordering of coal crystalline structure, resulting in increased coal oxidative reactivity. Similar relationships were also found in coal char [16].

Clearer trends are found between the five reactivity indexes with $I_{\mathrm{GR}} / I_{\mathrm{All}}$ and $I_{(\mathrm{G}+\mathrm{GR})} / I_{\mathrm{All}}$ compared with $I_{(\mathrm{S}+\mathrm{SL})} / I_{(\mathrm{G}+\mathrm{GR})}$. The latter has significantly higher standard deviations which indicates a weaker relationship with the reactivity index compared with those found for $I_{\mathrm{GR}} / I_{\mathrm{All}}$ and $I_{(\mathrm{G}+\mathrm{GR})} / I_{\mathrm{All}}$. Therefore, this may imply that the crystalline graphite structure associated with $\mathrm{G}$ band and aromatic ring systems associated with GR band are more important in determining the oxidation properties of coal compared with the disordered $\mathrm{sp}^{2}-\mathrm{sp}^{3}$ carbonaceous structures associated with S and SL bands. Importantly, however, there is a correlation between the Raman spectra and the reactivity index for 


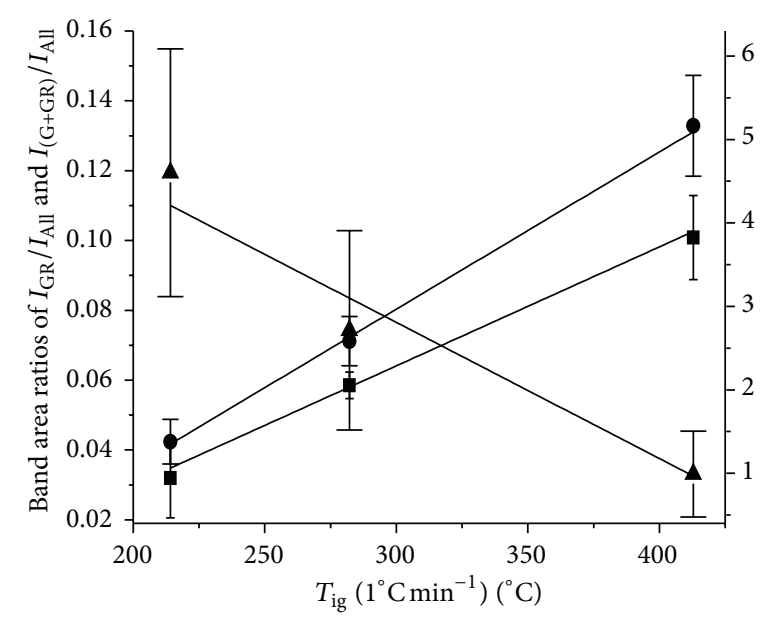

$$
\begin{aligned}
& \text { - } I_{\mathrm{GR}} / I_{\mathrm{All}} \\
& \text { - } I_{(\mathrm{G}+\mathrm{GR})} / I_{\mathrm{All}}
\end{aligned}
$$

\ $I_{(\mathrm{S}+\mathrm{SL})} / I_{(\mathrm{G}+\mathrm{GR})}$

(a)

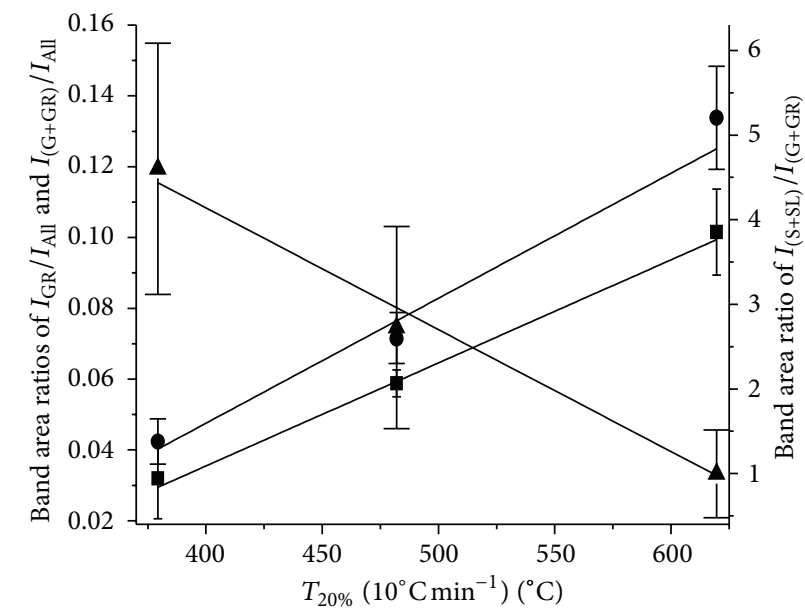

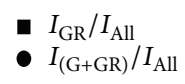$$
\text { - } I_{(\mathrm{S}+\mathrm{SL})} / I_{(\mathrm{G}+\mathrm{GR})}
$$

(c)

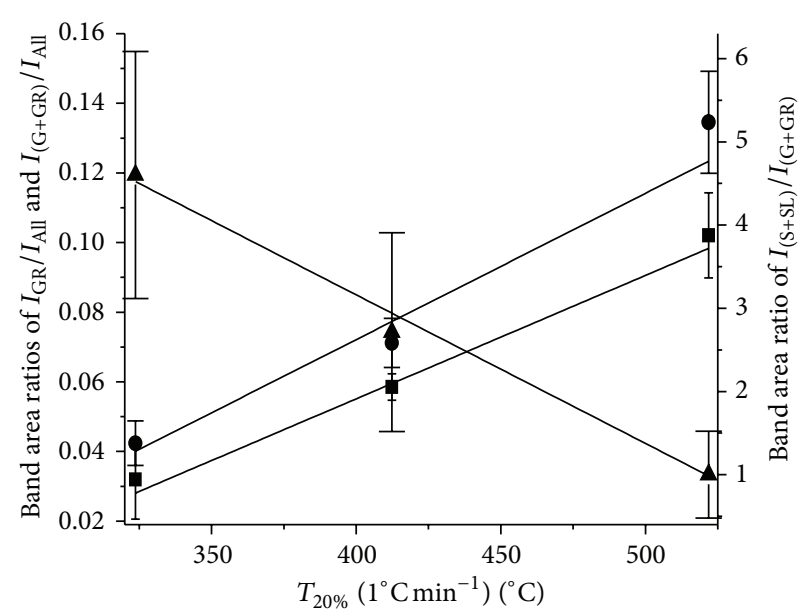

- $I_{\mathrm{GR}} / I_{\mathrm{All}}$

- $I_{(\mathrm{G}+\mathrm{GR})} / I_{\mathrm{All}}$

$\Delta I_{(\mathrm{S}+\mathrm{SL})} / I_{(\mathrm{G}+\mathrm{GR})}$

(b)

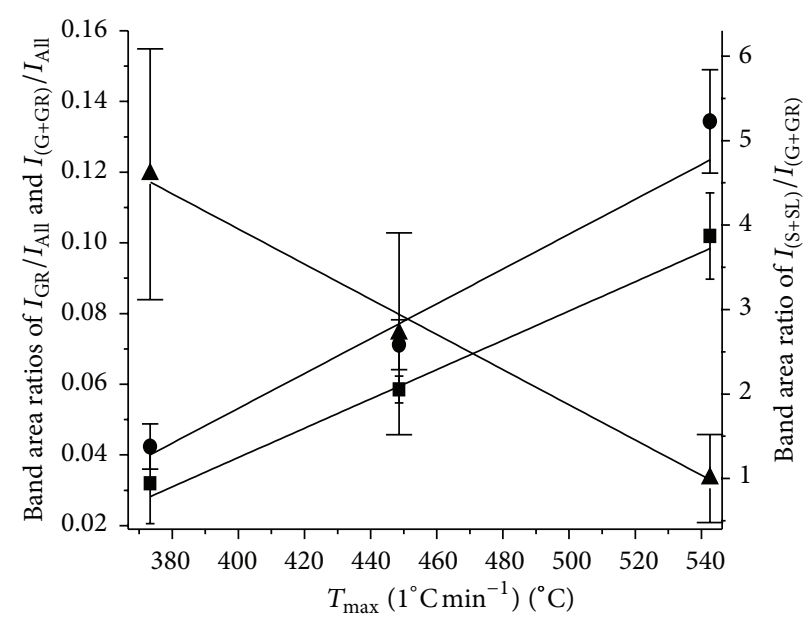

- $I_{(\mathrm{S}+\mathrm{SL})} / I_{(\mathrm{G}+\mathrm{GR})}$

(d)

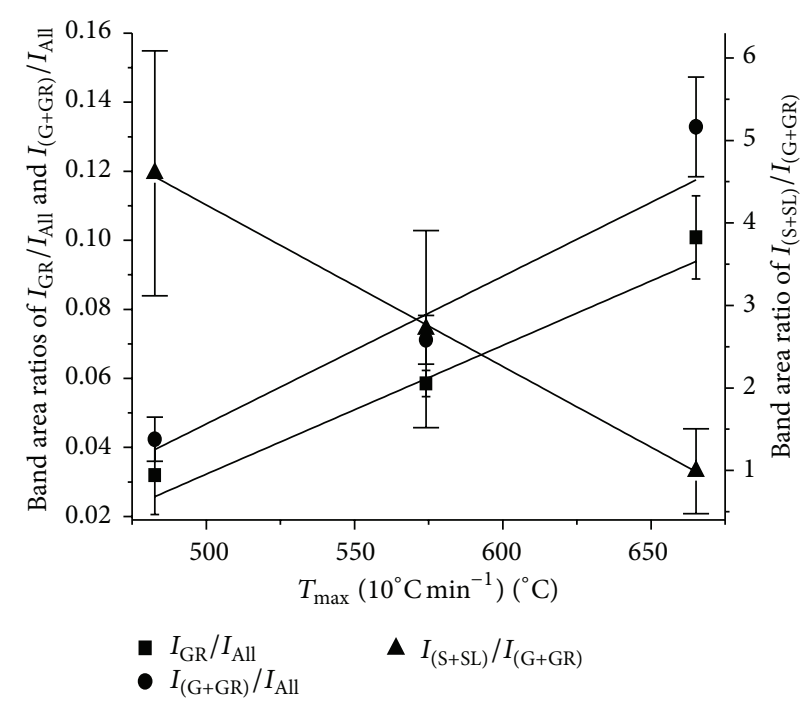

(e)

FIGURE 4: Different Raman band area ratios, $I_{\mathrm{GR}} / I_{\mathrm{All}}, I_{(\mathrm{G}+\mathrm{GR})} / I_{\mathrm{All}}$, and $I_{(\mathrm{S}+\mathrm{SL})} / I_{(\mathrm{G}+\mathrm{GR})}$, correlated with coal reactivity indexes: (a) $T_{\mathrm{ig}}\left(1^{\circ} \mathrm{C} \mathrm{min}{ }^{-1}\right)$, (b) $T_{20 \%}\left(1^{\circ} \mathrm{C} \mathrm{min}{ }^{-1}\right)$, (c) $T_{20 \%}\left(10^{\circ} \mathrm{C} \min ^{-1}\right)$, (d) $T_{\max }\left(1^{\circ} \mathrm{C} \min ^{-1}\right)$, and (e) $T_{\max }\left(10^{\circ} \mathrm{C} \mathrm{min}{ }^{-1}\right)$, respectively. The error bars show the standard deviations of the parameters for each coal sample. 
TABLE 2: Reactivity indexes characterizing oxidation reactivity of different rank coals.

\begin{tabular}{lcccc}
\hline $\begin{array}{l}\text { Parameter } \\
\left({ }^{\circ} \mathrm{C}\right)\end{array}$ & $\begin{array}{c}\text { Heating rate } \\
\left({ }^{\circ} \mathrm{C} \mathrm{min}^{-1}\right)\end{array}$ & Lignite & $\begin{array}{c}\text { Bituminous } \\
\text { coal }\end{array}$ & Anthracite \\
\hline \multirow{2}{*}{$T_{\mathrm{ig}}$} & 1 & 214.17 & 282.20 & 412.93 \\
\hline \multirow{2}{*}{$T_{20 \%}$} & 10 & - & 294.83 & 422.33 \\
\hline \multirow{2}{*}{$T_{\max }$} & 1 & 323.73 & 412.33 & 518.90 \\
& 10 & 379.33 & 481.17 & 617.50 \\
\hline
\end{tabular}

each type of coal indicating that these measurements may be used to provide a link between the structure of the coal and its oxidation.

\section{Conclusions}

Raman spectroscopy and TGA measurements were carried out for three different rank coals, lignite, bituminous coal, and anthracite, to examine whether the structural features observed could be related to the oxidation properties of the coal. Overall, the Raman spectral features showed that higher ranked coals had higher values of $I_{\mathrm{GR}} / I_{\mathrm{All}}$ and $I_{(\mathrm{G}+\mathrm{GR})} / I_{\mathrm{All}}$ but lower values of $I_{\mathrm{D}} / I_{(\mathrm{G}+\mathrm{GR})}, I_{\mathrm{DL}} / I_{(\mathrm{G}+\mathrm{GR})}, I_{(\mathrm{S}+\mathrm{SL})} / I_{(\mathrm{G}+\mathrm{GR})}$, and $I_{\left(\mathrm{GL}+\mathrm{GL}^{\prime}\right)} / I_{(\mathrm{G}+\mathrm{GR})}$, indicating an increase in the crystallinity of the coal and a decrease in the number of reacting sites and oxygen-containing structures. The changes in the intensity ratios were found to correlate with the reactivity indexes of coal obtained from TGA data. This indicated that the Raman band area ratios are related to the oxidation activity of coal and can provide additional structure information about coal.

\section{Conflict of Interests}

The authors declare that there is no conflict of interests regarding the publication of this paper.

\section{Acknowledgments}

The authors gratefully acknowledge the support from the Fundamental Research Funds for the Central Universities (2015QNA59). Thanks also go to technicians in ASEP and QUILL Research Centre of The Queen's University of Belfast for TGA and Raman spectroscopic measurements.

\section{References}

[1] H. H. Wang, B. Z. Dlugogorski, and E. M. Kennedy, "Lowtemperature oxidation of coal at elevated pressures," Journal of Loss Prevention in the Process Industries, vol. 11, no. 6, pp. 373381, 1998.

[2] M. A. Smith and D. Glasser, "Spontaneous combustion of carbonaceous stockpiles. Part I: the relative importance of various intrinsic coal properties and properties of the reaction system," Fuel, vol. 84, no. 9, pp. 1151-1160, 2005.

[3] J. V. Ibarra, E. Muñoz, and R. Moliner, "FTIR study of the evolution of coal structure during the coalification process," Organic Geochemistry, vol. 24, no. 6-7, pp. 725-735, 1996.
[4] R. Pietrzak and H. Wachowska, "Low temperature oxidation of coals of different rank and different sulphur content," Fuel, vol. 82, no. 6, pp. 705-713, 2003.

[5] C. Moon, Y. Sung, S. Ahn, T. Kim, G. Choi, and D. Kim, “Thermochemical and combustion behaviors of coals of different ranks and their blends for pulverized-coal combustion," Applied Thermal Engineering, vol. 54, no. 1, pp. 111-119, 2013.

[6] F. Tuinstra and J. L. Koenig, "Raman spectrum of graphite," Journal of Chemical Physics, vol. 53, no. 3, pp. 1126-1130, 1970.

[7] R. A. Friedel and G. L. Carlson, "Difficult carbonaceous materials and their infra-red and Raman spectra. Reassignments for coal spectra," Fuel, vol. 51, no. 3, pp. 194-198, 1972.

[8] R. Vidano, "New lines in the Raman spectra of carbons and graphite," Journal of the American Ceramic Society, vol. 61, no. 1-2, pp. 13-17, 1978.

[9] T. W. Zerda, A. John, and K. Chmura, "Raman studies of coals," Fuel, vol. 60, no. 5, pp. 375-378, 1981.

[10] J. van Doorn, M. A. Vuurman, P. J. J. Tromp, D. J. Stufkens, and J. A. Moulijn, "Correlation between Raman spectroscopic data and the temperature-programmed oxidation reactivity of coals and carbons," Fuel Processing Technology, vol. 24, no. 1, pp. 407413, 1990 .

[11] E. Quirico, J.-N. Rouzaud, L. Bonal, and G. Montagnac, "Maturation grade of coals as revealed by Raman spectroscopy: progress and problems," Spectrochimica Acta Part A: Molecular and Biomolecular Spectroscopy, vol. 61, no. 10, pp. 2368-2377, 2005.

[12] C.-Z. Li, "Some recent advances in the understanding of the pyrolysis and gasification behaviour of Victorian brown coal," Fuel, vol. 86, no. 12-13, pp. 1664-1683, 2007.

[13] S. Potgieter-Vermaak, N. Maledi, N. Wagner, J. H. P. Van Heerden, R. Van Grieken, and J. H. Potgieter, "Raman spectroscopy for the analysis of coal: a review," Journal of Raman Spectroscopy, vol. 42, no. 2, pp. 123-129, 2011.

[14] R. Tsu, G. H. Jesus, H. C. Isaac, and C. A. Luengo, "Raman scattering and luminescence in coal and graphite," Solid State Communications, vol. 24, no. 12, pp. 809-812, 1977.

[15] P. D. Green, C. A. Johnson, and K. M. Thomas, "Applications of laser Raman microprobe spectroscopy to the characterization of coals and cokes," Fuel, vol. 62, no. 9, pp. 1013-1023, 1983.

[16] C. Sheng, "Char structure characterised by Raman spectroscopy and its correlations with combustion reactivity," Fuel, vol. 86, no. 15, pp. 2316-2324, 2007.

[17] X. Li, J.-I. Hayashi, and C.-Z. Li, "FT-Raman spectroscopic study of the evolution of char structure during the pyrolysis of a Victorian brown coal," Fuel, vol. 85, no. 12-13, pp. 1700-1707, 2006.

[18] A. Sadezky, H. Muckenhuber, H. Grothe, R. Niessner, and U. Pöschl, "Raman microspectroscopy of soot and related carbonaceous materials: spectral analysis and structural information," Carbon, vol. 43, no. 8, pp. 1731-1742, 2005.

[19] A. Zaida, E. Bar-Ziv, L. R. Radovic, and Y.-J. Lee, "Further development of Raman microprobe spectroscopy for characterization of char reactivity," Proceedings of the Combustion Institute, vol. 31, pp. 1881-1887, 2007.

[20] O. Beyssac, B. Goffé, J.-P. Petitet, E. Froigneux, M. Moreau, and J.-N. Rouzaud, "On the characterization of disordered and heterogeneous carbonaceous materials by Raman spectroscopy," Spectrochimica Acta Part A: Molecular and Biomolecular Spectroscopy, vol. 59, no. 10, pp. 2267-2276, 2003. 
[21] T. Livneh, E. Bar-Ziv, O. Senneca, and P. Salatino, "Evolution of reactivity of highly porous chars from Raman microscopy," Combustion Science and Technology, vol. 153, no. 1, pp. 65-82, 2000.

[22] E. Bar-Ziv, A. Zaida, P. Salatino, and O. Senneca, "Diagnostics of carbon gasification by Raman microprobe spectroscopy," Proceedings of the Combustion Institute, vol. 28, no. 2, pp. 23692374, 2000.

[23] O. O. Sonibare, T. Haeger, and S. F. Foley, "Structural characterization of Nigerian coals by X-ray diffraction, Raman and FTIR spectroscopy," Energy, vol. 35, no. 12, pp. 5347-5353, 2010.

[24] C. Avila, T. Wu, and E. Lester, "Estimating the spontaneous combustion potential of coals using thermogravimetric analysis," Energy \& Fuels, vol. 28, no. 3, pp. 1765-1773, 2014.

[25] C. Avila, T. Wu, and E. Lester, "Petrographic characterization of coals as a tool to detect spontaneous combustion potential," Fuel, vol. 125, no. 2, pp. 173-182, 2014.

[26] K. Nestler, D. Dietrich, K. Witke, R. Rössler, and G. Marx, "Thermogravimetric and Raman spectroscopic investigations on different coals in comparison to dispersed anthracite found in permineralized tree fern Psaronius sp.," Journal of Molecular Structure, vol. 661-662, no. 1-3, pp. 357-362, 2003.

[27] L. Lu, V. Sahajwalla, C. Kong, and D. Harris, "Quantitative X-ray diffraction analysis and its application to various coals," Carbon, vol. 39, no. 12, pp. 1821-1833, 2001.

[28] J. Zhan, H.-H. Wang, S.-N. Song, Y. Hu, and J. Li, "Role of an additive in retarding coal oxidation at moderate temperatures," Proceedings of the Combustion Institute, vol. 33, no. 2, pp. 25152522, 2011.

[29] H. Gan, S. P. Nandi, and P. L. Walker Jr., "The nature of the porosity in American coals," Fuel, vol. 51, no. 4, pp. 272-277, 1972.

[30] H. H. Wang, B. Z. Dlugogorski, and E. M. Kennedy, "Coal oxidation at low temperatures: oxygen consumption, oxidation products, reaction mechanism and kinetic modelling," Progress in Energy and Combustion Science, vol. 29, no. 6, pp. 487-513, 2003.

[31] P. A. Morgan, S. D. Robertson, and J. F. Unsworth, "Combustion studies by thermogravimetric analysis: 1. Coal oxidation," Fuel, vol. 65, no. 11, pp. 1546-1551, 1986.

[32] M. V. Kök, "Temperature-controlled combustion and kinetics of different rank coal samples," Journal of Thermal Analysis and Calorimetry, vol. 79, no. 1, pp. 175-180, 2005.

[33] S. L. Niu, C. M. Lu, K. H. Han, and J. L. Zhao, "Thermogravimetric analysis of combustion characteristics and kinetic parameters of pulverized coals in oxy-fuel atmosphere," Journal of Thermal Analysis and Calorimetry, vol. 98, no. 1, pp. 267-274, 2009.

[34] L.-Y. Wang, Y.-L. Xu, S.-G. Jiang et al., "Imidazolium based ionic liquids affecting functional groups and oxidation properties of bituminous coal," Safety Science, vol. 50, no. 7, pp. 1528-1534, 2012. 

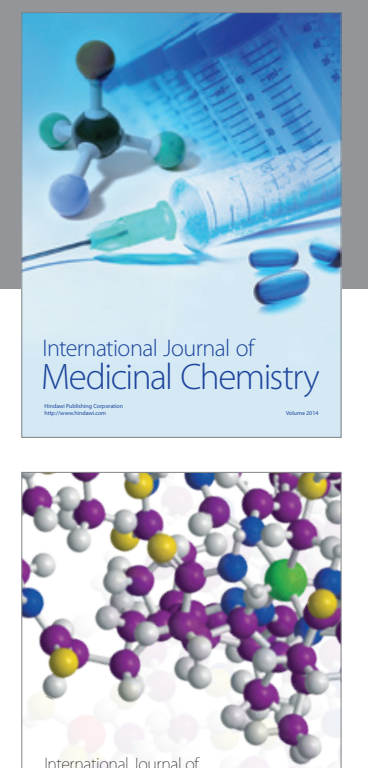

\section{Carbohydrate} Chemistry

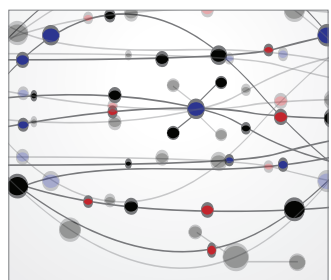

The Scientific World Journal
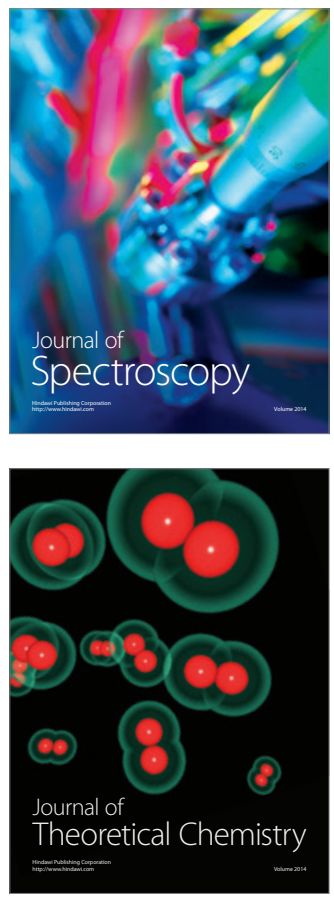
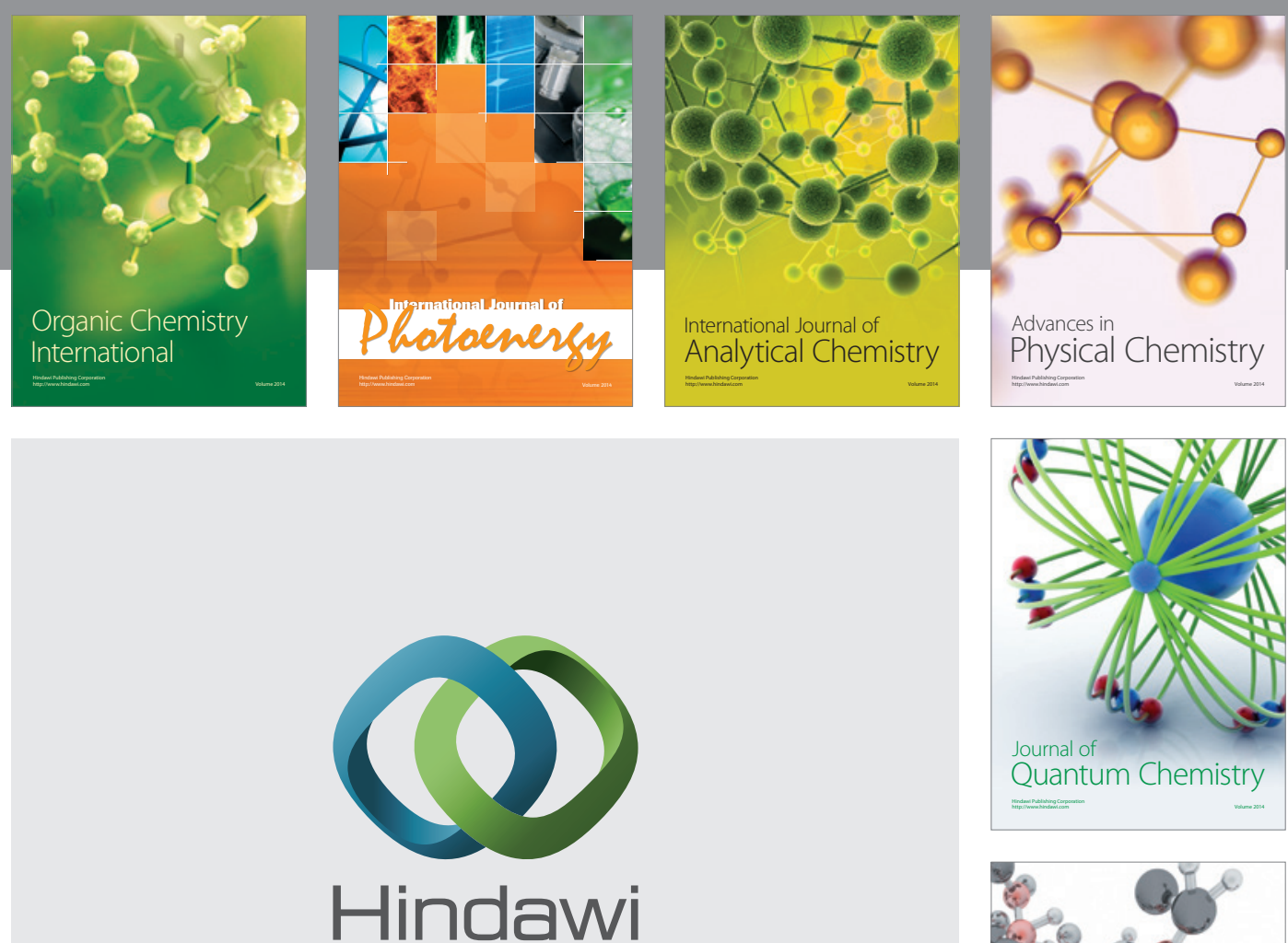

Submit your manuscripts at

http://www.hindawi.com

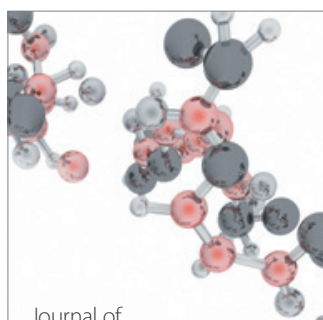

Analytical Methods

in Chemistry

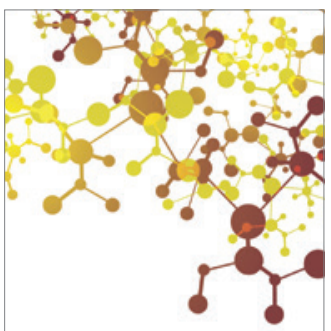

Journal of

Applied Chemistry

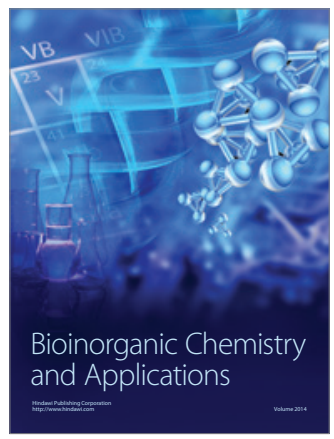

Inorganic Chemistry
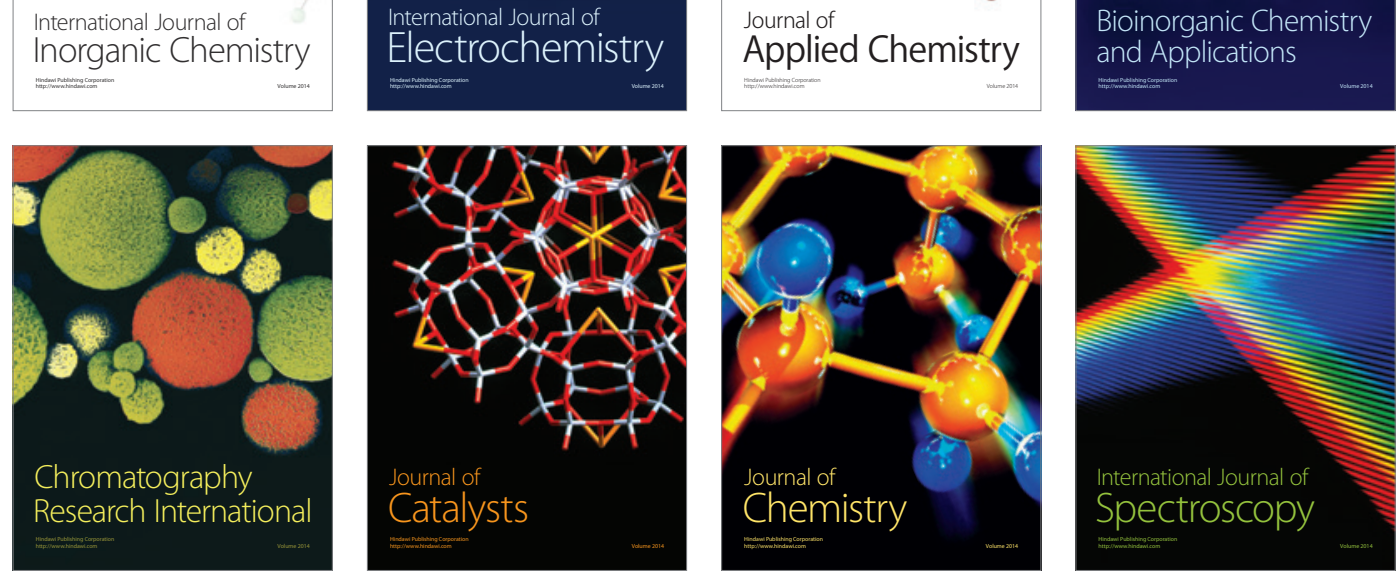